\title{
Cooproducción desde el Arte, la Ciencia y las nuevas Tecnologías
}

\author{
Co-production from the Arts, Science and New Technologies
}

\author{
Laura G. Olalde \\ UNTREF, Argentina \\ olaldelaura@gmail.com \\ Pablo Rodriguez \\ UBA, Argentina \\ manolo1416@yahoo.com
}

\author{
Diego U. Ferreiro \\ UBA, Argentina \\ diegulise@gmail.com \\ Alejandro D. Nadra \\ UBA, Argentina \\ alenadra@gmail.com
}

\begin{abstract}
This paper proposes the analysis of the interaction between artists and scientists (sci-art) through the experience of coproduction and the role of technology in the process of creation from multiple perspectives, taking as an object of study the representation of submicroscopic phenomena at the molecular scale of life. This paper is centered in the experience of creation of the work named Introversión Dogmática ("Dogmatic Introversion"), but other subjects related to the theoretical framework are also mentioned.
\end{abstract}

Keywords: Sci-art; Biología molecular; Bioarte; ADN; Proteínas

\section{Introducción}

En el campo científico, la creciente visualización de estructuras moleculares en pantalla, a partir de datos provenientes de estudios de cristalografía de rayos $X$, ha restringido al plano bidimensional su forma simbólica de representación, perdiendo la materialidad y el volumen de representaciones de antaño. Las nuevas tecnologías de impresión 3D ofrecen la posibilidad de arrojar esos datos hacia una nueva materialidad y tridimensionalidad escalable, recuperando su aspecto físico y estructural. La experiencia ha sido plasmada en la obra Introversión Dogmática.

\section{Diseño colaborativo desde la coproducción sci-art}

La emergencia de una zona de intercambio simétrico entre artistas y científicos está claramente ligada al desarrollo de nuevas herramientas informáticas y de equipos de muy alta resolución para la visualización de datos (Reising, 2009, p.2). El movimiento sci-art surge de esta interacción mediada por la tecnología. Bajo la forma colaborativa de coproducción, el objeto sci-art mantiene el vínculo ontológico con la información científica, pero mediado en su presentación por el lenguaje artístico. Al manipular cualidades de forma, escala, color e intensidad de las imágenes, se logra una fuerza de atracción en el espectador superior a la que se lograría sin estos arreglos, confiriéndole al objeto científico una estética "con belleza". De esta forma el arte genera una mediación entre éste y el público no especializado por medio de la ampliación de lectura de la información visual, operando como recurso cognitivo para la investigación científica.

\section{Procedimientos Metodológicos}

Introversión Dogmática es una coproducción artísticocientífica que discute tanto la cuestión del DOGMA CENTRAL de la biología molecular,
(https://es.wikipedia.org/wiki/Dogma central de la biolog\% C3\%ADa molecular), según el cual toda la información de los seres vivos estaría escrita en los genes en una secuencia de algoritmos ejecutables que transfieren información unidireccionalmente: $\quad \mathrm{ADN} \rightarrow \mathrm{ARN} \rightarrow$ proteínas, como la cuestión de la representación limitada a las dos dimensiones de una pantalla. Introversión Dogmática propone una mediación entre público y objeto científico por medio de una estetización diferente a la vigente de la representación científica de fenómenos nanoscópicos que ocurren en la escala molecular de lo viviente. Por otro lado, es una experiencia inmersiva para el espectador, que deviene medio asociado al sistema, que a su vez reacciona de acuerdo a la detección de su movimiento en el entorno.

\section{Descripción de la obra}

Introversión Dogmática se presenta como una instalación interactiva que consiste en una representación macro de la dinámica de la unidad nucleosomal conformada por proteínas histonas (https://es.wikipedia.org/wiki/Histona) y ADN (https://en.wikipedia.org/wiki/DNA). Estos componentes, obtenidos por la tecnología de impresión 3D (FDM) y luego copiados en caucho de silicona, guardan una escala diez millones de veces mayores respecto de las estructuras de alta resolución conocidas por medio de la tecnología de cristalografía de rayos $\mathrm{X}$, y ganan cierta flexibilidad al ser copiados en este material. La obra es una estilización rigurosa de un fenómeno nanoscópico realizada mediante la combinación apropiada de tecnologías usuales en prácticas científicas y artísticas.

Las cuestiones de escala en la representación, de generalidad (que nos indica que todos los organismos vivos tienen una constitución molecular similar) y de un enfoque no determinista como resultado del análisis de fenómenos epigénicos contrastables a partir de la 


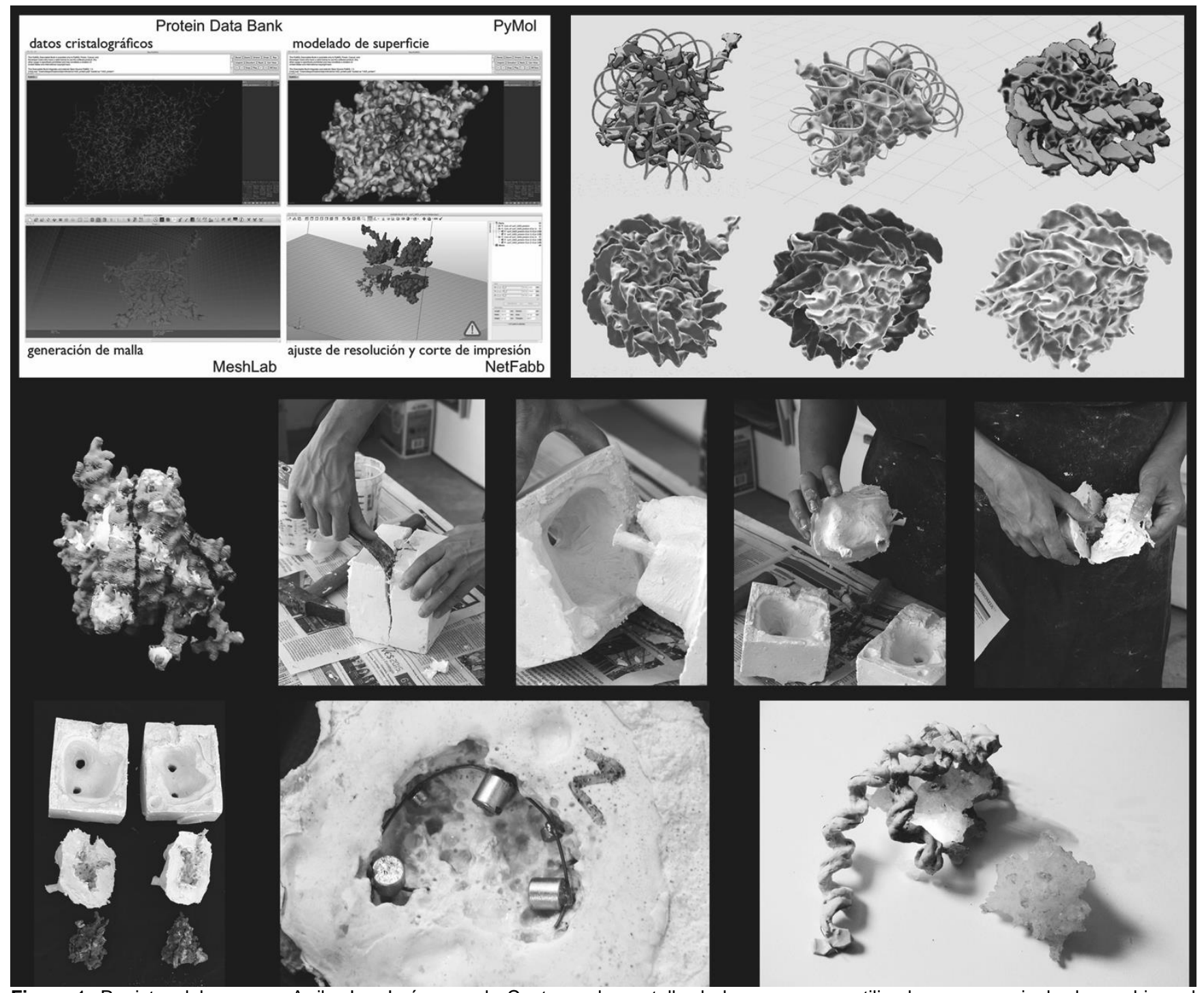

Figura 1: Registro del proceso. Arriba Izq. Imágenes de Capturas de pantalla de los programas utilizados para manipular los archivos de estructuras moleculares en formato PDB: PyMol, MeshLab y NetFabb. Arriba Derecha: Esquemas experimentales de representaciones de histonas y ADN. Los datos cristalográficos se obtuvieron del Protein Data Bank y se representaron con Molecular Flipbook, buscando el nivel de representación apropiado para la construcción de los prototipos. Abajo: secuencia de imágenes de realización de moldería de impresiones 3D y copias en caucho de silicona con incrustaciones de imanes.

\section{Descripción de los componentes del sistema}

La búsqueda de formas de representación tridimensionales alternativas a las usuales en pantalla como forma de visualización de la interacción de proteínas histonas y ADN nos enfrentó a la cuestión de escala y nos llevó a la búsqueda de texturas y materiales apropiados.

La construcción formal de los componentes del sistema guarda estricta relación con los estudios de cristalografía de rayos $\mathrm{X}$ descriptos. Estos modelos se originaron de la información disponible en el repositorio de proteínas PDB (Protein Data Bank) y fueron impresos en 3D siguiendo un protocolo desarrollado ad hoc utilizando software de acceso público. La impresión 3D fue la solución para mantener el rigor de correspondencia formal entre las estructuras descriptas en el caso de las proteínas histonas. (Figura 1)
Sin embargo, la búsqueda de una textura que nos remitiera a lo orgánico nos alejaba de la dureza del acabado plástico del material $A B S$ que nos brindaba la tecnología de impresión 3D. Como solución, optamos por incorporar al proceso técnicas de escultura para el copiado de las impresiones 3D en materiales acordes a la sensación buscada. Realizamos moldes de gran precisión en silicona RTV8001 e hicimos copias con ese mismo caucho y con caucho Silastic T2 traslúcido. Después de probar distintos tintes, lo descartamos porque a esa escala no hay color. A las piezas "histonas" se les incrustaron magnetos en correspondencia con los lugares observables en su interacción con el ADN, el cual tenía aleatoriamente magnetos a lo largo de su doble hélice de forma regular.

\section{Descripción del sistema}

Una vez resueltos los componentes, pasamos a integrarlos en un sistema con un medio asociado o entorno. Para el 
despliegue del sistema de las unidades moleculares en movimiento se incorporó el uso de un cilindro de acrílico montado en una base de hierro para la provisión de un medio acuático adecuado para el fenómeno representado. El cilindro, con una capacidad de 300 litros y un espesor de $6 \mathrm{~mm}$, fue el continente del sistema cuya superficie emulaba la estructura de una membrana celular. En el fondo del cilindro se colocaron bombas de agua que regulaban la circulación del flujo, promoviendo rupturas y acercamientos facilitados por los magnetos entre las unidades histona y ADN. La iluminación del sistema es independiente de la luz del entorno: para ello se realizó una matriz compuesta por 52 LEDs ultraluminosos concentrada en la tapa superior del cilindro. (Figura 2)

La interacción del sistema con el entorno está regulada por la detección de movimiento proveniente de un sensor PIR de alarma de pared, controlando el encendido y apagado de dos bombas de agua que imprimen la dinámica del sistema ya que producen turbulencia y variaciones en el flujo del medio líquido. También regula la iluminación del objeto dada por la matriz de LEDs ubicada en la parte superior del cilindro.

Los softwares utilizados para el modelado e impresión 3D son de licencia libre.

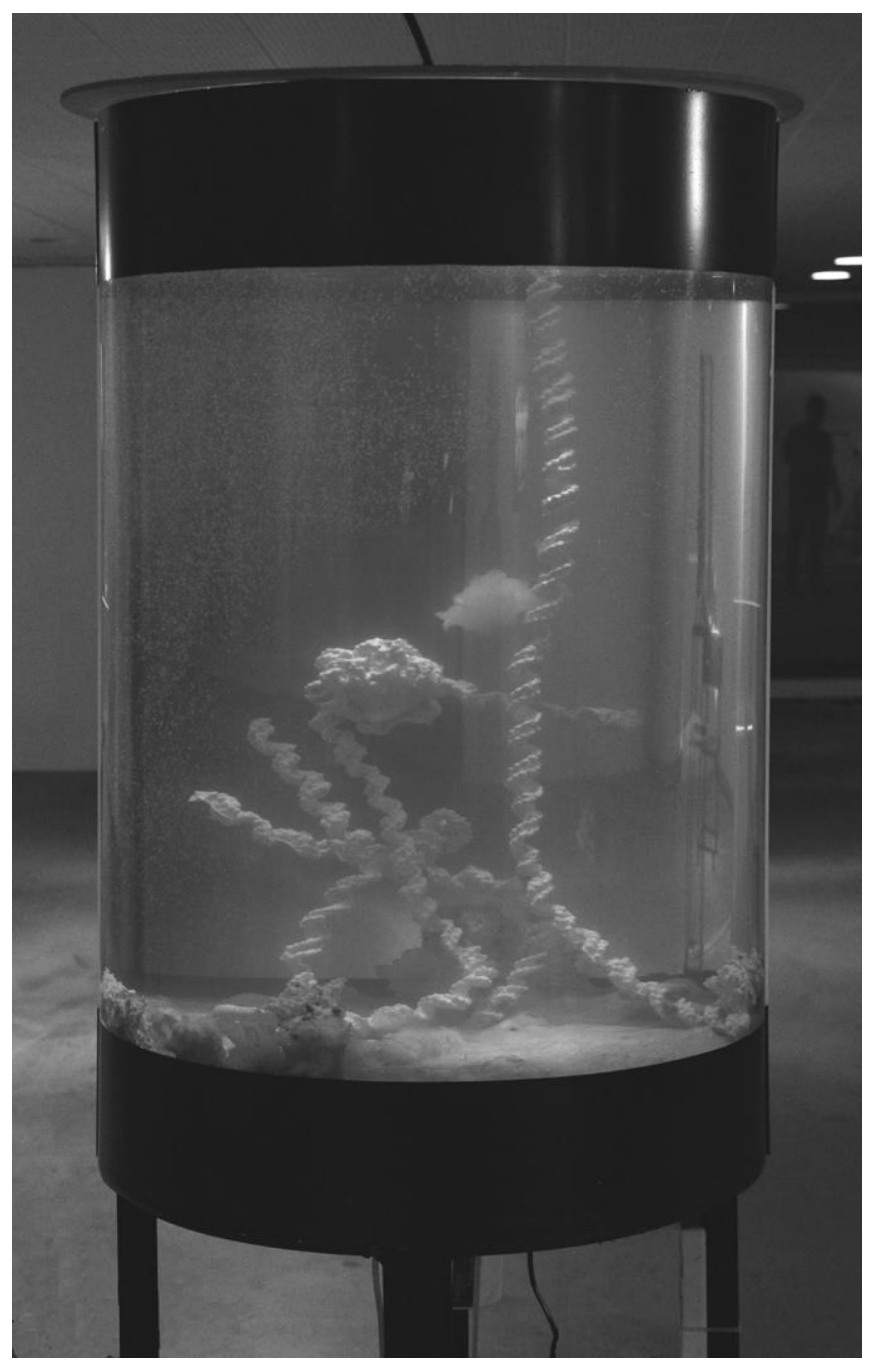

Figura 2: Introversión Dogmática, durante la exhibición del Premio ArCiTec, Marzo, 2015. Centro Cultural General San Martín.

\section{Equipo y dinámica de trabajo}

La realización de Introversión Dogmática estuvo a cargo de los integrantes del Colectivo PROTEUS, conformado por los biólogos moleculares Diego Ferreiro y Alejandro Nadra y por Laura Olalde, artista. Contó con los desinteresados aportes de colegas, amigos y expertos de áreas tan específicas como la de acuarios, de moldería en escultura, de impresiones 3D y de desarrollo visual y comunicación. La historia del Colectivo nos remonta a 2013 con un encuentro casual de sus integrantes en Garagelab (www.garagelab.cc), espacio ecléctico de Buenos Aires, facilitador de intercambios entre gente proveniente de distintos campos con ideas para compartir. Unos meses después de ese encuentro y luego de un Curso de Biología Sintética dictado en la Facultad de Ciencias Exactas y Naturales de la UBA en el que confluyeron participantes de muy diversas formaciones, estaban surgiendo los lineamientos de Introversión Dogmática, en base a las siguientes premisas de trabajo:

\section{Generar una comunidad de interacción.}

Acercar(nos) recursos, links, referencias y herramientas propias de cada área a compartir.

Comenzar ensayos alrededor de inquietudes comunes para su prototipado.

Desarrollar la apreciación estética a escala macroscópica.

Fue a mitad de 2014 que nos propusimos la materialización de alguna de las muchas ideas que brotaban de reunión en reunión y encontramos en el Concurso ArCiTec de Arte, Ciencia y Tecnología, organizado por UTN, la excusa perfecta para entrar en fase de concreción práctica.

La primera etapa de trabajo se desarrolló principalmente a partir de sucesivas reuniones en el Laboratorio de Fisiología de Proteínas en la Facultad de Ciencias Exactas y Naturales, UBA. Durante ese tiempo, entre octubre y noviembre de 2014, proliferaron las impresiones 3D y la búsqueda de técnicas para superar las limitaciones de las texturas resultantes propias de los materiales de impresión. Se comenzaron entonces los ensayos en otros materiales. (Figura 3)

Mientras se resolvían los componentes, se estudió una primera versión consistente en una plataforma vibratoria que originalmente había sido pensada como soporte físico de los componentes (histonas y ADN). A través de su movimiento vibratorio se buscaba obtener las transiciones conformacionales esperadas. Sin embargo, esta idea fue desestimada por ser demasiado ruidosa por los motores excéntricos que la movían, por no corresponderse con la naturaleza del medio intracelular, mayoritariamente compuesto por agua $\mathrm{y}$, fundamentalmente, por resultar insuficiente para generar la dinámica esperada. Una vez redefinidos los aspectos formales y previa reunión con la productora del evento, procedimos al desarrollo en escala del proyecto definitivo. Los almuerzos y reuniones en el 
SIGraDi 2016, XX Congreso de la Sociedad Ibero-americana de Gráfica Digital 9-11, November, 2016 - Buenos Aires, Argentina

laboratorio se alternaron con las reuniones y jornadas de producción de taller, donde todos metimos mano en cada cuestión práctica de la obra. Un verdadero intercambio de

rutinas, itinerarios, saberes y trayectorias del "taller al labo y del labo al taller". (Figura 4).

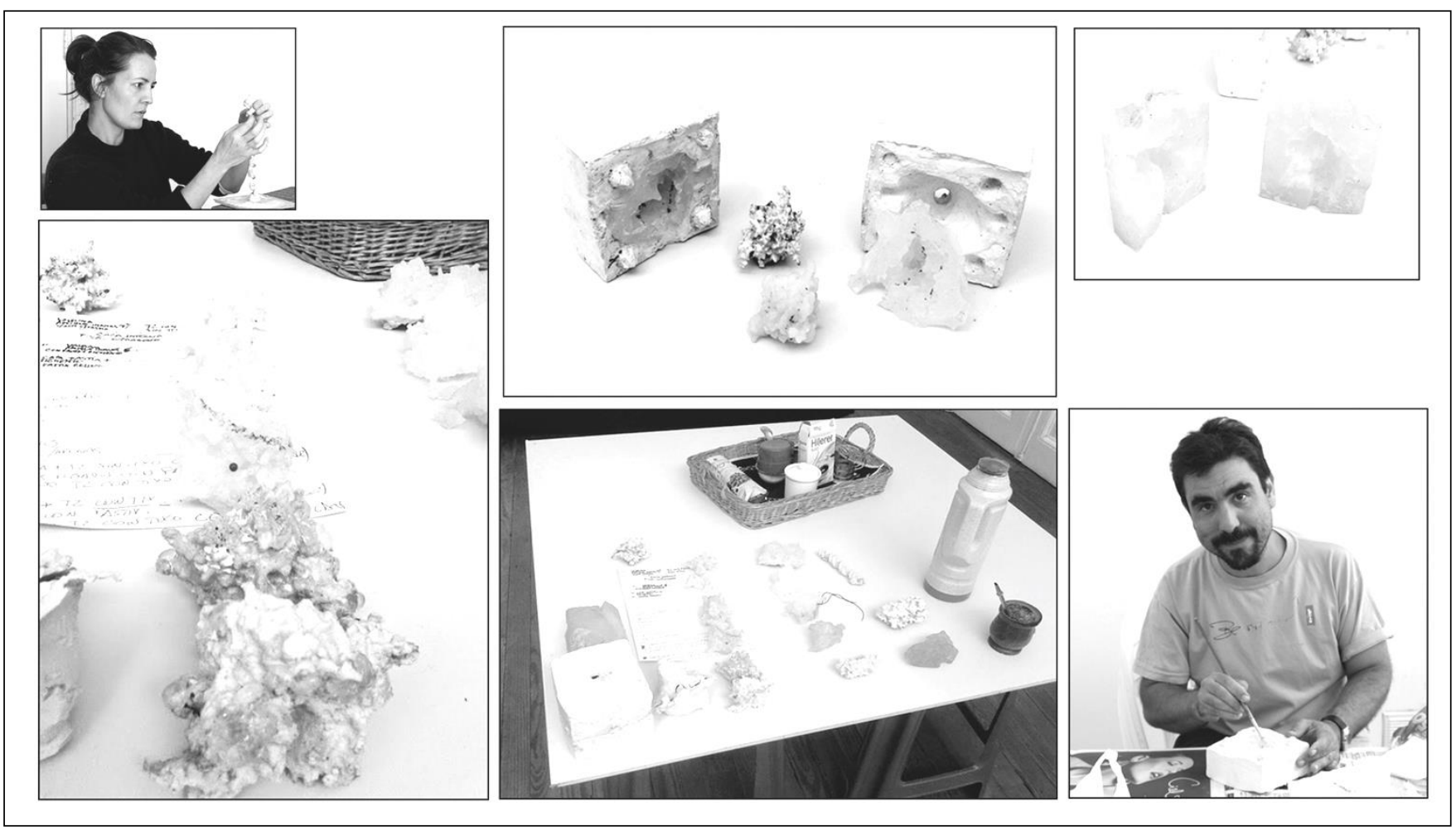

Figura 3: Verano de 2015 en el taller. Realización de componentes. Integración de técnicas escultóricas.

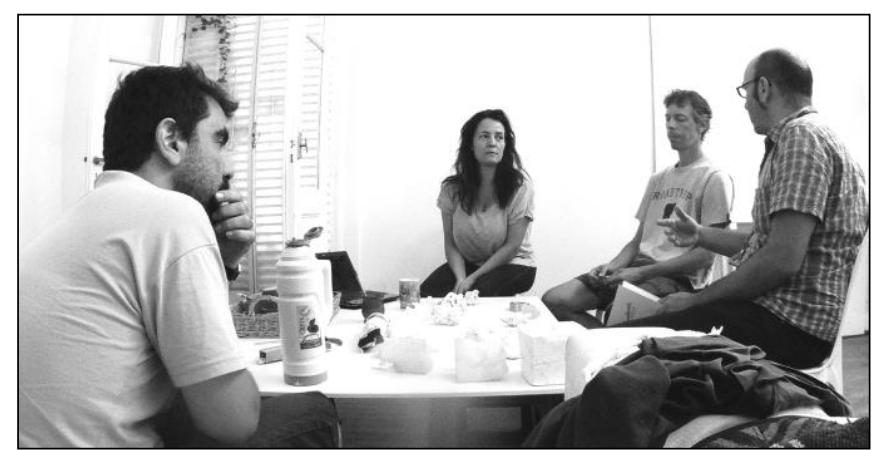

Figura 4: Verano de 2015 en el taller. Intercambio de conceptos con Federico Geller, encargado de la comunicación e infografías del proyecto. exhibición de Introversión Dogmática como parte del Premio ArCiTec, donde obtuvo Mención del jurado. La exposición se llevó adelante en marzo de 2015 en el Centro Cultural General San Martín y la propuesta tuvo amplia recepción por parte del público que se acercaba con preguntas relativas al sistema representado.

La experiencia formó parte de la investigación para la Tesis de Maestría en Artes Electrónicas de UNTREF titulada "Visión compuesta desde el Arte, la Ciencia y las nuevas Tecnologías iSalí de la pantalla!", de Laura Olalde, integrante de PROTEUS, proveyendo un marco de referencia para su desarrollo.

\section{Resultados}

Histonas y ADN interactúan en el interior de un cilindro contenedor de agua, que hace las veces de membrana celular y continente del sistema conformado. Se tocan, se encuentran, se pegotean y se desprenden. Esta interacción sucede por la detección de movimiento en el entorno que introduce "ruido" en el sistema generando las variaciones, aproximaciones y los enlaces descriptos entre sus componentes. La escala tangible de las unidades permitió que los espectadores pudieran tocar y vincular a los componentes expuestos en pedestales junto con las infografías explicativas (Figura 5), completando el marco de 


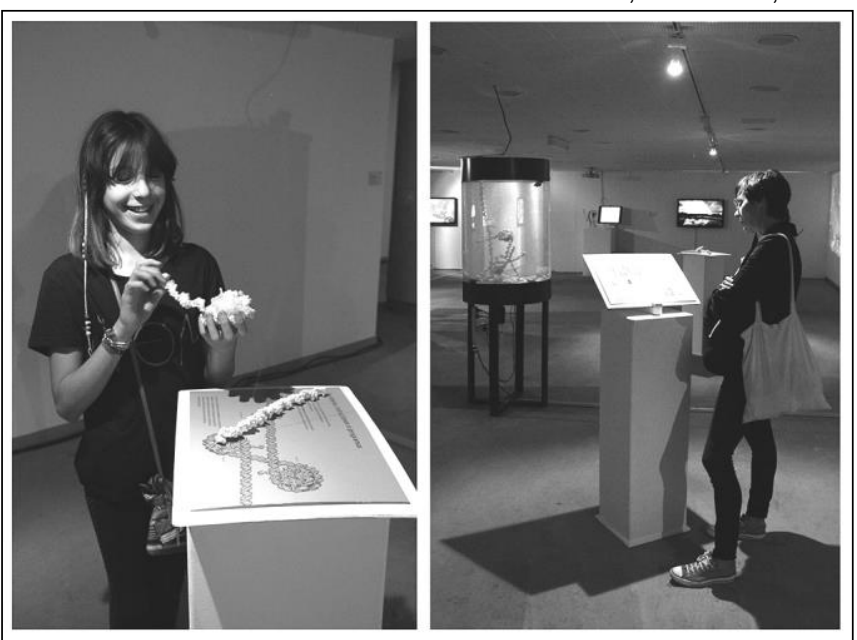

Figura 5: Interacción obra público. CCGSM, marzo 2015. La disposición de infografías relativas a las cuestiones de escala, generalidad y antideterminismo facilitaron un segundo nivel de análisis de la propuesta por parte del público.

\section{Discusión}

Si entendemos a "la imagen como la referencia de cierto aspecto del mundo que contiene en su propia estructura una referencia al acto de cognición que la genera" (Cohen, 1979, p.24), entonces el paso cualitativo de la percepción de una imagen bidimensional a la tridimensionalidad expandiría ese mismo aspecto del mundo, ofreciendo nuevos modelos teóricos para el conocimiento científico y nuevas perspectivas para su apreciación estética. Introversión Dogmática explora esta hipótesis, ya que es a la vez un experimento sobre los límites de la representación científica vigente y una propuesta de otra visión que además interviene teóricamente en el campo de la biología molecular con el cuestionamiento al Dogma Central.

Nos proponemos explorar formas alternativas de representación científica ante un cierto "malestar" que habla de transformaciones culturales en la percepción, acostumbrada al plano de la pantalla y a imágenes digitales contemporáneas que dan la falsa seguridad de "realismo de síntesis numérica". Se trata de imágenes que el ojo humano nunca podrá captar y lo que se representa es lo que se sabe del objeto de estudio a partir de datos computacionales de las estructuras observadas, cuyo referente es el algoritmo del programa que las determina.

\section{Conclusiones}

La creciente cooperación entre arte y ciencia ha dado forma al actual movimiento conocido como sci-art, que aparece ante nuestros ojos como un horizonte de posibilidades para la coproducción de objetos y contenidos que, por su novedad, escapan a las categorías tradicionales de clasificación tanto del ámbito científico como del artístico. Como ejemplo podemos nombrar las prácticas descriptas en el área de bioarte, que aún con un recorrido de casi 20 años de producción todavía encuentra entre los teóricos dificultades para su definición y un público perplejo en su recepción. Este desconcierto en relación con las nuevas prácticas en arte y ciencia recuerda la recepción de todos los movimientos artísticos que marcaron una ruptura con los cánones estéticos dominantes de su tiempo.

Las coproducciones sci-art orientadas a la (re)presentación de fenómenos observables a través de tecnologías de alta resolución, como por ejemplo la cristalografía de rayos $\mathrm{X}$, nos permiten acceder a la información molecular y a la constitución atómica de la materia. Esa información es sometida a diversos análisis por medio de procedimientos computacionales para su estudio a través de modelos teóricos para las ciencias, a la vez que revela patrones de organización de la materia que se expresan como cualidades plásticas plausibles de sucesivas operaciones técnicas de adquisición de forma con fines artísticos. Este potencial devenir de la información obtenida podría ser el principio de individuación característico del objeto sci-art.

La experiencia de trabajo de coproducción sci-art del Colectivo PROTEUS está signada por ese potencial polidireccional que apunta a una construcción conjunta y permeable, como proceso que deviene en forma. El interés colectivo por la dinámica de los sistemas vivientes a escala molecular nos condujo a la problemática de la información en la materia viva mediada por sucesivas operaciones técnicas conducentes a su representación. La selección de los sucesivos pasos de transformación técnica resultó en una ineludible reflexión conjunta en relación con los sistemas de representación visuales usuales en el campo de la investigación científica por un lado y de la producción artística por otro. El resultado es la instalación Introversión Dogmática.

El cuestionamiento de la naturalización de la pantalla como medio de representación bidimensional de fenómenos tridimensionales observables a través de tecnologías de alta resolución fue el disparador en la búsqueda de nuevas posibilidades de expresión de la información a través de la tecnología de impresión 3D. La posibilidad de su materialización a escala tangible humana fue posible gracias al mencionado potencial polidireccional de la información. Podríamos decir que nuestro objeto de estudio fue la información en la materia con la intención de lograr una apertura en la recepción del usuario/espectador. Esta expansión de la percepción a través de los sentidos y de la posibilidad de elaborar esquemas corporales relativos a fenómenos que nos resultan intangibles e invisibles a partir del trabajo de la magnificación de su escala, abrió el campo de experimentación sobre nuevos soportes. Para ello fue necesario romper con la experiencia mediada por la pantalla. Fue necesario el ensayo de un espacio de libertad tanto para el cuerpo de la información como para el cuerpo del observador, restringido usualmente a su estático rol como usuario de pantalla desde un punto de vista único e inmóvil.

Introversión dogmática es el resultado de una búsqueda de expansión de los límites. No es una experiencia de bioarte, tampoco un ejercicio de divulgación científica. Es una experiencia física de la información. Es un objeto, un objeto sci-art.

\section{Agradecimientos}

Agradecemos todos los aportes de colegas y amigos que acompañaron el desarrollo de esta experiencia. Los aportes del Dr. Ignacio Sánchez codirector del Laboratorio de 
Fisiología de Proteínas de la Universidad de Buenos Aires que contribuyó a la formación del equipo en los inicios del proyecto. A UTN Buenos Aires por ofrecer el marco adecuado para la exhibición y difusión de la obra en enmarco del Premio Arcitec. A la Empresa de Acrílicos Lamanna, que proveyó desinteresadamente el soporte que dio cuerpo a la obra.

Un agradecimiento especial a quienes simplemente creyeron incondicionalmente y aportaron consejos, experiencia técnica, compañía y amistad. A Mauro Tambella, experto en acuarios que nos orientó en la búsqueda de insumos apropiados para la realización de la obra. A Federico Geller encargado de la comunicación gráfica de nuestra propuesta. A Gerardo Gabriel Della Vecchia por su ayuda técnica.

\section{Referencias}

Cohen, Harold. (1979). What is an image?. University of California at San Diego. Consultada el 5 de mayo de 2015 en http://www.aaronshome.com/aaron/publications/index.html

Goodsell, David (2009). The machinery of life. New York, N.Y: Springer Science + Business Media.

Gould, Stephen Jay (1996). Escalas y conos: La evolución ilimitada por el uso de iconos canónicos. En R. B. Silvers (Ed.) Historias de la ciencia y del olvido. (pp. 123-54). Madrid: Siruela.

Lewontin, R. C.; Rose, S., \& Kamin, Leon J. (1984). Not in our genes: biology, ideology, and human nature. New York, NY: Pantheon Books.

Machado, Arlindo (2000). El paisaje mediático: sobre el desafío de las poéticas tecnológicas. Buenos Aires: Universidad de Buenos Aires.

Reising, Ailin María. (2009). La reunificación de las "dos culturas" a través de la vía tecnológica: implicancias estéticas y cognitivas del movimiento sci-art. En I Encuentro Internacional de Culturas Científicas y Alternativas Tecnológicas.

Ramirez, Rodrigo et al. (2015). Panorama de la Impresión 3D. Buenos Aires: Instituto Nacional de Tecnología Industrial (INTI).

Simondon, Gilbert. (2009). La individuación a la luz de las nociones de forma e información. Buenos Aires: Ediciones La Cebra y Editorial Cactus.

Steimberg, Leo. (1972). El arte contemporáneo y la incomodidad del público. En Other Criteria, Confrontation with Twentieth-Century Art. Oxford: Oxford University Press. 